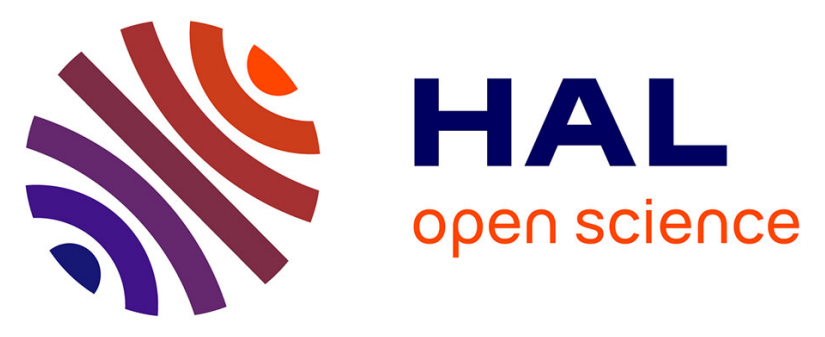

\title{
Modelling the Effect of Cerastoderma edule Bioturbation on Microphytobenthos Resuspension Towards the Planktonic Food Web of Estuarine Ecosystem
}

Christiane Rakotomalala, Karine Grangeré, Martin Ubertini, Martin Forêt, Francis Orvain

\section{To cite this version:}

Christiane Rakotomalala, Karine Grangeré, Martin Ubertini, Martin Forêt, Francis Orvain. Modelling the Effect of Cerastoderma edule Bioturbation on Microphytobenthos Resuspension Towards the Planktonic Food Web of Estuarine Ecosystem. Ecological Modelling, 2015, 316, pp.155-167. 10.1016/j.ecolmodel.2015.08.010 . hal-03227917

\section{HAL Id: hal-03227917 https://hal.science/hal-03227917}

Submitted on 17 May 2021

HAL is a multi-disciplinary open access archive for the deposit and dissemination of scientific research documents, whether they are published or not. The documents may come from teaching and research institutions in France or abroad, or from public or private research centers.
L'archive ouverte pluridisciplinaire HAL, est destinée au dépôt et à la diffusion de documents scientifiques de niveau recherche, publiés ou non, émanant des établissements d'enseignement et de recherche français ou étrangers, des laboratoires publics ou privés. 
4

5

6

7

8

9

\section{Modelling the Effect of Cerastoderma edule Bioturbation on Microphytobenthos Resuspension Towards the Planktonic Food Web of Estuarine Ecosystem}

\section{Christiane Rakotomalala ${ }^{\text {a }}$, Karine Grangeré ${ }^{\text {a }}$, Martin Ubertini ${ }^{\text {a }}$, Martin Forêt ${ }^{\text {a }}$ and Francis} Orvain ${ }^{a^{*}}$

a Université de Caen Basse-Normandie, UMR BOREA MNHN, UPMC, UCBN, CNRS-7208, IRD-207, F-14032 Caen, France

*Corresponding author: Francis Orvain

Email: francis.orvain@unicaen.fr

Tel: 0033 (0)2 31565116

Fax number: 0033 (0)2 31565346

6

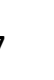

8

19

0


Abstract

Microphytobenthos (MPB) represents an important food source for primary consumers in estuarine ecosystems and the availability of MPB as food items results from complex physical, chemical, and biological interactions. In Baie des Veys (Lower Normandy, France), the common cockle Cerastoderma edule constitutes the major bioturbator in the ecosystem in terms of biomass. In this ecosystem, cockle bioturbation is a key process regulating the MPB erosion flux in the water column. This bivalve intensely modifies the top layer of the sediment by increasing the sediment erodibility and the fluxes of suspended chlorophyll $a$ through the valve movements. More precisely, cockle bioturbation destabilizes the sediment surface by creating a biogenic layer that is easily eroded with tidal hydrodynamic forces. Associated MPB can then be exported to the water column to fuel higher trophic levels of the planktonic food web. The aim of this study was to develop a numerical model that reproduces the export of MPB associated to the biogenic layer erosion. Kinetics of suspended MPB, in response to increasing stress, were obtained from flume experiments in lab controlled conditions and in situ natural conditions. Following this, the suspended MPB were analyzed to respectively parameterize the model by 1) a calibration approach, and 2) an independent validation. The analysis has highlighted that the higher the biomass of cockles, the higher the MPB resuspension rates. Our model consistently reproduces the tendency encountered in laboratory analysis and with in situ natural conditions. During the validation, a small site-specific lack of adjustment was identified, but, among the macrozoobenthic community, the model can be significantly improved by considering the bioturbation activities of another ecosystem engineer, Pygospio elegans. This study thus provides reliable estimates of the daily food availability from benthic primary consumers in an estuarine system where cockles dominate the bioturbating assemblage. This model can be inserted in various model designs (0D, 1Dvertical or 3D).

Keywords: sediment transport, erodibility, modelling, microphytobenthos, Cerastoderma edule, bioturbation

0




\section{Introduction}

Numerical modelling represents a useful tool to overcome complexity and temporal variations of marine ecosystems. It has been used to reproduce physical transport on tidal flat temporal pattern in estuarine system (e.g. Toorman 2002). Such complex models simulate the temporal pattern of tidal flats through hydrodynamic disturbances which integrate sediment suspension and circulation (Cancino and Neves, 1999; Chao et al., 2008; Clarke and Elliott, 1998; Warner et al., 2008). Moreover, sediment erosion may also be mediated by biological activities (Kristensen et al., 2012; Orvain et al., 2012; Widdows and Brinsley, 2002; Willows et al., 1998; Wood and Widdows, 2002). Biology can affect the sediment properties through faunal bioturbation process described by the same authors. Bioturbation is a key process in coastal system and greatly modifies the physical properties of the sediment (Andersen et al., 2010; Ciutat et al., 2006). Macrofauna bioturbation can stabilize or destabilize the sediment depending on the species. Macrozoobenthos changes the erodibility of the sediment. This process of ecosystem functioning has been modelled by simulating the bioturbation effect of macrofauna on sediment stability (Orvain, 2005; Orvain et al., 2003; Willows et al., 1998). Orvain et al. (2012) have validated a model of bioturbation effect of two macrofauna species (Scrobicularia plana and Peringia ulvae) on sediment erodibility. They stated that the effect of bioturbation on sediment properties remains a species-specific process. Moreover, Kristensen et al. $(2012,2013)$ clearly showed that faunal erosion impacts must preferably be evaluated in biomass units when developing bioturbation/erosion laws, however erosion laws remain species-specific (Kristensen et al., 2012; Orvain et al., 2012). Species such as the bivalve Scrobicularia plana have strong erosion impact in the sediments they inhabit while Peringia ulvae have strong surface effects, especially when compared in biomass unit. Peringia ulvae also have strong grazing effects on microphytobenthic biofilms (Orvain, 2005; Orvain et al., 2014) and the important surface area can be rapidly covered, even by one single individual (Orvain et al. 2012).

Moreover, the study of the benthic autotrophic compartment has also been modeled with special focus on the role of microphytobenthos (MPB) resuspension and the dynamics of its biomass (Guarini et al., 2008; Mariotti and Fagherazzi, 2012). Export of MPB in the water column is a key process that maintains the biofilm development and avoids the saturation of MPB development in the sediment (Blanchard et al., 2001). A realistic simulation of resuspension of MPB biofilm can be obtained only if this process is not associated to the strong erosion of the underlying sediment (Guarini et al. 2008). The mass bed erosion is a strong event that has a too drastic influence on chlorophyll $a$ biomass dynamics to let develop the biofilm at a sustainable equilibrium state. The model developed by Guarini et al. (2008) represents detachment process that continually and moderately affects the benthic marine MPB biofilms under low hydrodynamic forces. In nature, such chronic detachment of benthic microalgae can be assumed to be equivalent to the commonly named "fluff layer erosion" by Shimeta et al. (2002) and Orvain et al. (2003), mainly related to bioturbation activities (Orvain et al., 2004). Mariotti and Fagherazzi (2012) have developed a model of growth and resuspension of MPB biofilm development under hydrodynamic disturbances. The chronic detachment of MPB biofilm was integrated in a simple manner in the model, which corresponds to the resuspension of MPB described by Guarini et al. (2008). They have also integrated the erosion of the sediment in the model, which occurs in a case of high hydrodynamic forcing, and traditionally considered as "bed erosion" (type Ib or type II 
erosion, according to the definition by Amos et al. (1992). Mariotti and Fagherazzi (2012) have pointed out that the intensity, the frequency of hydrodynamic disturbances, and the time scale dynamic of MPB growth are decisive factors for MPB temporal pattern.

The common cockles (Cerastoderma edule) move in their environment and rework the sediment particles, modifying the chemical and physical properties of their habitats (Hedman et al., 2011). There is some controversy about the effect of this species on sediment erodibility. The destabilizing (Ciutat et al., 2006, 2007) or stabilizing (Andersen et al., 2010) effect of cockles has been counteracted. Nonetheless, Andersen et al. (2010) have highlighted the stabilizing effect of MPB biofilm, such as other studies have found in absence of fauna (Sutherland et al., 1998; Underwood and Paterson, 1993). Also, they explained the lack of destabilizing effect of cockles in their results as the direct consequence of the entirely buried position of cockle during the experiments. They then stated that the position of the cockle in the sediment can increase the bed roughness. Otherwise, species-specific behavior such as filtration, valve movement, and burying activity, common to the cockle, disturbs the sediment and leads to the erosion of sediment at a lower shear stress as compared to an undisturbed sediment. Experiments conducted by Jonsson et al. (2005) also support the assumption that cockles directly consume a part of suspended algal matter, playing a key role by disturbing turbulence in the benthic boundary layer. Cockles can thus be considered as an engineer species that physically disturbs sediment and water column allowing MPB availability in the ecosystem.

To the best of our knowledge, there is a dearth of modelling the export of MPB in the water column associated to sediment erosion due to macrofaunal bioturbation. We need to bridge the gap between modelling the chronic detachment of MPB and the fluff layer erosion in a bioturbated system, to better evaluate the role of these ecosystem engineers. The purpose of this study was to assess the predictability of MPB erosion by using bioturbation/erosion laws that have only been used in the past for modelling sediment transport (Orvain et al., 2012) in a bioturbated system. More specifically, we aimed at refining the way to model the 'chronic' fluff layer erosion and the associated MPB under the bioturbation action of the bivalve Cerastoderma edule in the Baie des Veys (Normandy-France), where this species drastically dominates the wild macrofaunal community (Ubertini et al., 2012). The objective of this study was to model the erosion rate of MPB in response to various body sizes and densities of cockles and thereby determine the food availability of benthic primary producers for the cockles and associated suspension-feeders in estuarine ecosystems. The model of fluff layer erosion has been parameterized with experimental data by following a 2-step approach: 1) calibration of erosion parameters related to bioturbation on the basis of experimental data in controlled lab conditions, cockle density and body size, and 2) validation performed with in situ data from three locations in the Baie des Veys (Normandy-France). The validation step was conducted without readjusting the parameters to assess the model fitness to independent in situ data. The residuals between modelled and observed data were computed to discuss fitting adjustment.

2. Data

2.1 Laboratory experiments

Experiments were conducted to determine the effects of cockle bioturbation on the resuspension rates of microphytobenthic biofilm in the water column. Density effect of juveniles $(0.25-1.4 \mathrm{~cm})$ and adult cockles $(2.2-2.7 \mathrm{~cm})$ were experimented. Erosion was conducted with the Erodimeter flume. Details of the functioning of the flume are explained in 
Le Hir et al. (2008). The device allowed the imposition of controlled bed shear velocities $\left(\mathrm{u}^{*}\right.$ ca $1.40-4 \mathrm{~cm} \mathrm{~s}^{-1}$ ) on sediment cores of microphytobenthos and cockle culture. Tested velocities were incrementally increased every 5 minutes, constituting the forcing factor for the model developed later. Probes connected to the flume recorded continually: i) the flow discharge; ii) the pressure upstream and downstream the sediment core; iii) the turbidity; and iv) the suspended Chlorophyll $a$ biomass (calibrated with the fluorimetry). Following the method of Guizien et al. (2012), the bed shear stress $\left(\tau_{\mathrm{f}}, \mathrm{Pa}\right.$ or $\left.\mathrm{kg} \mathrm{m}^{-1} \mathrm{~s}^{-2}\right)$ was calculated. The recorded fluorescence was also converted in quantity of chlorophyll (Chl $a_{\text {probe }}, \mu \mathrm{gChl} a \mathrm{~L}^{-1}$ ) in the water column. Chl $a_{\text {meas, }}$ which represents the quantity of eroded chlorophyll $a$ per unit of area $\left(\mu \mathrm{gChl} a \mathrm{~m}^{-2}\right)$ was deduced with the product of chlorophyll $a$ concentration ( $\mu \mathrm{gChl} a$ $\left.\mathrm{L}^{-1}\right)$ and the volume of the Erodimeter (L) over the surface of the core $\left(\mathrm{m}^{2}\right)$. Water was sampled at 3 different flows $\left(1.65,2.97,3.94 \mathrm{~cm} \mathrm{~s}^{-1}\right)$, was filtered with Whatman filters $(\mathrm{GF} / \mathrm{C}$ $47 \mathrm{~mm}$ ), and treated to determine the concentration of suspended matter (in $\mathrm{g} \mathrm{L}^{-1}$ ) and the concentration of suspended chlorophyll $a$ (in $\mu \mathrm{g} \mathrm{L}^{-1}$ ).

\subsection{Chlorophyll $a$ correction}

Studies conducted by Jonsson et al. (2005) have shown direct consumption of a part of suspended matter exported in the water column by cockles. A high resolution camera was placed over the sediment cores during the erosion experiments. Time during which an active filtration occurred $\left(t_{\text {fil }}, s\right)$ was then deduced from siphon movement. Given that cockles filtered a certain quantity of suspended chlorophyll $a$ during the experiments, the filtration relationship developed by Rueda et al. (2005) was used to quantify the microphytobenthic chlorophyll $a$ consumed during the experimental time. The rate at which the cockle filters $\left(\mathrm{Chl} a_{\mathrm{fil}}, \mu \mathrm{gChl} a \mathrm{~m}^{-2} \mathrm{~s}^{-1}\right)$ depends on the clearance rate $\left(\mathrm{CR}, \mathrm{L} \mathrm{m}^{-2} \mathrm{~s}^{-1}\right)$ and the chlorophyll $a$ concentration in the water ( $\mathrm{Chl} a_{\text {probe }}, \mu \mathrm{gChl} a \mathrm{~L}^{-1}$ ). We used the recorded chlorophyll $a$ in the flume to estimate the filtration rate.

$$
\text { Chl } a_{\text {fil }}=\text { Chl } a_{\text {probe }} \times C R
$$

The clearance rate (CR, $\left.\mathrm{L} \mathrm{m}^{-2} \mathrm{~s}^{-1}\right)$, in agreement with the cockle growth model by Rueda et al. (2005), was deduced from the biomass of cockle (biomass, gDWcockle $\mathrm{m}^{-2}$ ) and the rate at which an organism of $1 \mathrm{~g}$ of dry weight filters the chlorophyll $a$ biomass $\left(\mathrm{A}_{\mathrm{cr}}, \mathrm{L}\right.$ gDWcockle ${ }^{-1}$ $\left.\mathrm{s}^{-1}\right)$.

$$
C R=A_{c r} \times \text { Biomass }
$$

The total amount of suspended chlorophyll $a\left(\mathrm{Chl} a_{\mathrm{tot}}, \mu \mathrm{gChl} a \mathrm{~m}^{-2}\right)$ is thereafter corrected by artificially adding the cumulative sum of filtered chlorophyll $a\left(\mathrm{Chl} a_{\mathrm{fil}}\right)$ during the period of active filtration ( $\left.\mathrm{t}_{\text {fil }}, \mathrm{s}\right)$ to the measured chlorophyll $a\left(\mathrm{Chl} a_{\text {meas }}, \mu \mathrm{gChl} a \mathrm{~m}^{-2}\right)$.

$$
\text { Chl } a_{\text {tot }}=\text { Chl } a_{\text {meas }}+\text { Chl } a_{f i l} \times t_{f i l}
$$

Corrections were made due to the fact that the model will reproduce the resuspension of MPB without the filtration process of cockle. The model development presented herein is based on data from the aforementioned experiments and the model was thus calibrated with the total resuspended chlorophyll $a\left(\mathrm{Chl} a_{t o t}\right)$. Parameters and equations of filtration activity of cockles are summarized in Tab. 1.

\subsection{Validation data}

Independent datasets were obtained from a temporal survey of the cockle population dynamic in the Baie des Veys (Lower-Normandy France) in June and September 2012, January and April 2013. The survey was conducted at low tide at 3 sites in the Baie des Veys (Fig. 1i): A, $\mathrm{B}$, and $\mathrm{C}$.

Two series of samplings were conducted per site and per date. The first series consists of analyzing the macrofaunal composition and the chlorophyll $a$ content of the sediment (Fig. 
1ii, gray circles). Samplings were made in 5 stations per site (Fig. 1ii). Quadruplicate samples of macrofauna and Chlorophyll $a$ content were made per station. Analysis of each sample was conducted separately. Macrofauna were sampled with a $0.25 \mathrm{~m}^{2}$ quadrat of $0.15 \mathrm{~m}$ depth, then were extracted from the sediments with sieve of $1 \mathrm{~mm}$ mesh size. Thereafter, macrofauna species were identified and counted. The chlorophyll $a$ content of the sediment was determined by sampling the surface layer with a disc of $20 \mathrm{~cm}$ diameter and $1 \mathrm{~cm}$ depth. Sediment sample was homogenized and freeze-dried during 12h. Following the method conducted by Welschmeyer (1994), chlorophyll $a$ was extracted with acetone during 24 hours at dark from $200 \mathrm{~g}$ of dried sediment. Chlorophyll $a$ was then measured with fluorometer whose values were expressed in quantity of chlorophyll $a$ per $\mathrm{g}$ of sediment $(\mu \mathrm{gChl} a$ gDWsediment ${ }^{-1}$ ).

The second series consists of sampling sediment cores to analyze the erodibility of the sediment (Fig. 1ii, black circles). Samplings were conducted on-site in 3 stations chosen randomly among the 5 stations (Fig. 1ii). Three sediment cores were sampled in each station for the flume experiments (Erodimeter). In total, 9 extra sediment cores were sampled each date. The same experimental procedure as during laboratory experiments was adopted, during which resuspended chlorophyll $a$ was continuously measured. The filtered chlorophyll $a$ in the recirculating flume was estimated in the same way as in laboratory experiments, and when cockles were present in the sediment core. The total resuspended chlorophyll $a$ was used for the validation step. Cockle specimens from the erosion experiments were thereafter captured at the end of the experiments and individually weighed to provide the biomass of cockles responsible of bioresuspension in the flume. Since the core of sediment used with the flume experiment was sampled in situ, other macrofauna species were present in the sediment.

Among the 36 erosion experiments, only 18 experiments with live and active cockles were analyzed and were used to validate the model. Thus, the corresponding samples of macrofauna and chlorophyll $a$ in the sediment were considered for further analyses.

Kruskal-Wallis nonparametric tests were conducted to analyze temporal and spatial differences between sites regarding chlorophyll $a$ content and macrofauna composition (because the conditions for parametric ANOVA were not fulfilled).

3. Model development

3.1 Conceptualization

Fig. 2 represents concepts and processes which are taken up in this study. The water column constitutes one single compartment. The second compartment is represented by the sediment where cockles are present. The link between the two compartments is represented by the flux due to erosion $\left(\mathrm{E}_{\mathrm{btb}}\right)$. Filtration by cockles $\left(\mathrm{Chl} a_{\mathrm{fil}}\right)$ is also represented in Fig. 2 and was used to determine the total suspended chlorophyll $a$ as explained earlier. Two bioturbation effects of cockle on the sediment are considered in the present study: (1) the increase of bed roughness, and (2) the bioresuspension of MPB due to valve adduction. Cockle effect on bed roughness was not modelled but the bed shear stress, affected by cockles, was measured and directly used as the forcing variable. A 0-dimension model design was chosen to be developed on the basis of the aforementioned bio-destabilizing effects of cockles on sediment. Fluxes resulting from advection and diffusion exchanges are neglected in our approach.

\subsection{Model equations}

In this study, three state variables are used and units are given it Tab. 2: the suspended chlorophyll $a(\mathrm{SChl} a)$, the suspended matter (SPM), and the biogenic matrix $\left(\mathrm{Q}_{\mathrm{btb}}\right)$. Previous works of Orvain et al. (2003) describe the total suspended matter with the following equation:

$$
\frac{d S P M}{d t}=E_{b e d}+E_{b t b}-D
$$


$E_{b e d}, E_{b t b}$, and $D$ are respectively the bed eroded flux, the bioresuspension flux and the deposition flux. First, type Ia erosion $\left(\mathrm{E}_{\mathrm{btb}}\right)$ occurred in relation to detached aggregates produced by bioturbation activities, and then Type Ib or II 'catastrophic' erosion ( $\left.\mathrm{E}_{\text {bed }}\right)$ takes place at the moment when the critical bed shear stress $\left(\tau_{\text {crit-bed }}\right)$ is reached resulting in a massive increase of suspended matter (Orvain et al., 2003). This process also refers to the classical bed erosion (type $\mathrm{Ib}$ ) related to consolidation effects or sand/mud mixtures (Amos et al., 1992). The superficial bioresuspension $\left(\mathrm{E}_{\mathrm{btb}}\right)$ requires a low shear stress comparable to the hydrodynamic forcing during a flood/ebb tide.

However, the erosion of the underlying bed sediment requires a greater shear velocity and is correlated with the burying activity of cockles. Since the goal of our study is to model the resuspension of MPB associated to the fluff layer (Type Ia), the value of the Type Ib and II bed erosion $\left(\mathrm{E}_{\mathrm{bed}}\right)$ was artificially removed in the model, and the experimental dataset was restricted to the first part of the curve before catastrophic erosion. The process of catastrophic erosion is related to wind-induced stress in coastal ecosystems. This phenomenon is, however, out of the scope of the present study, in which we focus on chronic MPB erosion related to cockle bioturbation and not sediment transport or MPB long-term dynamics. We suppose that, within the range of experienced shear velocities, the deposition of matter is directly resuspended in the water column. The Eq. 4 is then simplified as follows and is used as the next step of model development.

$$
\frac{d S P M}{d t}=E_{b t b}
$$

The value of the bioresuspension critical shear stress $\left(\tau_{\text {crit-fluff, }}\right.$ Pa or $\left.\mathrm{kg} \mathrm{m}^{-1} \mathrm{~s}^{-2}\right)$ is determined differently depending two situations. In a case of an overlap of the 2 types of erosion (Ia and $\mathrm{Ib})$, means of SPM were directly linearized.

$$
S P M=a \times u^{*}+b
$$

where $\mathrm{u}^{*}\left(\mathrm{u}^{*}, \mathrm{~cm} \mathrm{~s}^{-1}\right)$ corresponds to the current velocity.

In a case when a plateau of SPM is reached (erosion type Ia), mean values were first power transformed and thereafter linearized.

$$
10^{S P M}=a \times u^{*}+b
$$

The zero value of SPM corresponds to the value at which the erosion is initiated at the critical shear velocity $\left(u_{\text {crit-fluff }}, \mathrm{cm} \mathrm{s}^{-1}\right)$. The corresponding critical shear stress $\left(\tau_{\text {crit-fluff }}\right)$ is deduced from a linear relationship between the critical shear velocity, corresponding to the initiation point of erosion, and the seawater density $\rho\left(\mathrm{kg} \mathrm{m}^{-3}\right)$.

$$
\tau_{\text {crit-fluff }}=\rho \times u_{\text {crit-fluff }}{ }^{2}
$$

As long as erosion takes place, the quantity of sediment contained within the biogenic matrix diminishes. The variation of the bioturbated sediment (the third state variable) over time depends on the erosion flux.

$$
\frac{d Q_{b t b}}{d t}=-E_{b t b}
$$

The extent of sediment resuspension $\left(E_{b t b}\right.$, gDWsediment $\left.\mathrm{m}^{-2} \mathrm{~s}^{-1}\right)$ depends, in part, on the physical forcing factor mainly represented by the shear stress $\tau_{\mathrm{f}}(\mathrm{Pa})$. The Partheniades formulation (1965) modified by Orvain et al. (2003) is then used to calculate the sediment resuspension flux $E_{b t b}$ which is a product of the excess of shear stress $\left(\tau_{f} / \tau_{\text {crit-fluff }}-1\right)$, the erosion coefficient $\alpha\left(\mathrm{s}^{-1}\right)$, and the amount of bioturbated sediment $\left(\mathrm{Q}_{\mathrm{btb}}, \mathrm{gDW}\right.$ sediment $\left.\mathrm{m}^{-2}\right)$.

$$
\begin{aligned}
& E_{b t b}=\alpha \times Q_{b t b} \times\left(\frac{\tau_{f}(t)}{\tau_{\text {crit-fluff }}}-1\right) \\
& \text { when } \tau_{f}(t)>\tau_{\text {crit-fluff }} \text { if not } E_{b t b}=0
\end{aligned}
$$

Before the erosion (so given as initial condition $t=0$ ), the suspended matter (SPM) is equal to 0 and quantity of bioturbated sediment $\left(\mathrm{Q}_{\mathrm{btb}}(\mathrm{t}=0)\right.$, $\mathrm{gDW}$ sediment $\left.\mathrm{m}^{-2}\right)$ is obtained from the product of the traces height of cockle on the sediment $h_{b t b}(m)$, and the dry density within traces $\rho_{\text {fluff }}\left(\mathrm{gDW}\right.$ sediment $\mathrm{m}^{-3}$ ). 
Experimental results (see section 4.1) showed that the biomass of cockles represents a relevant factor that determines the cockle bioturbation on sediment. The bioturbated sediment depends linearly on the biomass of cockle (Biomass, $\mathrm{g}$ DW cockle $\mathrm{m}^{-2}$ as a forcing variable) and the bioturbated volume of sediment per $g$ of cockle $A_{b t b}\left(\mathrm{~m}^{3} \mathrm{~g}^{-1} \mathrm{DW}\right.$ cockle). The process is traduced conceptually with the trace height which represents the depth of the bioturbated sediment if the material uniformly covers the surface area at the beginning of the erosion.

$$
h_{b t b(t=0)}=A_{b t b} \times \text { Biomass }
$$

During the erosion, the trace height decreases according to the variation of the bioturbated sediment $\left(\mathrm{Q}_{\mathrm{btb}}\right.$, gDWsediment $\left.\mathrm{m}^{-2}\right)$.

$$
h_{b t b}=\left(\frac{Q_{b t b}(t)}{\rho_{\text {fluff }}}\right)
$$

The first state variable SChl $a\left(\mu \mathrm{gChl} a \mathrm{~m}^{-2}\right)$ is obtained by converting the suspended matter (SPM) into suspended chlorophyll $a$ with a conversion factor sedtochla. The equation (5) then becomes:

$$
\frac{d s C h l a}{d t}=E_{b t b} \times \text { sedtochla }
$$

The mentioned conversion factor sedtochla represents the slope of the linear relationship between suspended matter and the chlorophyll $a$, both obtained from water filtration mentioned earlier (see the end of the section 2.1).

Equations and parameters of the developed model are summarized in the Tab. 2.

3.3 Model parameterization and validation

Simulations of suspended MPB in the water column under the influence of cockle bioturbation were performed with the determination of two parameters. The first parameter is $\mathrm{A}_{\mathrm{btb}}$ (Eq. 12) which represents the bioturbated volume of sediment per $\mathrm{g}$ of cockle. The second parameter is $\alpha$ (Eq. 10): the erosion coefficient and corresponds to the rate at which the bioturbated sediment is eroded. Parameterization of the model is performed using the minimization with the Simplex method (Nelder and Mead, 1965) by minimizing the ordinary least squares criterion (Sum of Squared Error).

$$
S C E=\sum\left(S C h l a-C h l a_{t o t}\right)^{2}
$$

Simultaneous estimation of the two parameters was performed by minimizing the error (SCE) to simulate the chronic detachment of MPB in the water column.

Then, different approaches were conducted to evaluate how the model fits the measurements. Modelling efficiency (ME), as described in Vanclay and Skovsgaard (1997) was calculated with the following equation:

$$
M E=1-\frac{\sum\left(S C h l a-C h l a_{t o t}\right)^{2}}{\sum\left(S C h l a-\overline{C h l ~}_{t o t}\right)^{2}}
$$

Where $C h l a_{t o t}$ represents the observations and SChl $a$ the corresponding predictions. $\overline{C h l ~}_{\text {tot }}$ stands for the mean of the observations. A ME equals to 1 shows that the model fits well with the observation. A ME equals to zero means that the model is not better than a simple average and a negative value corresponds to bad fit.

Theil's inequality coefficient can be also used to evaluate the accuracy of the simulations. The same equation used by Lo et al. (2011) was used to calculate the coefficient.

$$
U=\sqrt{\frac{\sum\left(\text { Chl } a_{t o t}-S C h l a\right)^{2}}{\sum C h l a_{t o t}{ }^{2}}}
$$

A value of $U$ equals to zero represents perfect simulations. $U$ equals to 1 represents simulations which is not better than considering unchanging variable. $U$ higher than 1 represents bad simulations. 
Test of equivalence (Robinson and Froese, 2004) using a null hypothesis was also conducted with the R software package 'equivalence' (Robinson et al., 2005). The robust two one sides test for equivalence was used on simulated and observed data.

To explain discrepancies between model results and measurement residuals between all total suspended chlorophyll $a$ (Chl $\left.a_{\mathrm{tot}}\right)$ and all respective simulated chlorophyll $a$ (SChl $a$ ) were confronted with biomasses of macrofaunal major species and also confronted with chlorophyll $a$ content in the sediment.

\section{Results}

4.1 Laboratory experiments and chlorophyll $a$ correction

The percentage of resuspended benthic chlorophyll $a$ is linearly correlated with the cockle biomass $\left(r^{2}=0.78, p<0.001\right)$ (Fig.3) which reflects how the matrix of sediment susceptible of being eroded responds to the biomass of the burrowing bioturbator. Formation of bioturbated sediment is thus a function of cockle biomass in a system where cockle is the dominant bioturbator species.

The measurement of chlorophyll $a$ in the water column traduces the quantity of MPB exported in the water column associated to the erosion of the biogenic matrix. Chlorophyll $a$ resuspension in the water column increases with increasing shear stress and increasing biomass of cockle. Suspended chlorophyll $a$ during experiments with adult cockles is much higher than with juvenile individuals (Fig.4a).

The analyses of the kinetics of chlorophyll $a$ have shown two types of erosion that occurred during the flume experiments (Fig.4a): fluff layer (or 'chronic erosion', type Ia according to the definition by Amos et al. 1992) and bed erosion (Type Ib or II 'catastrophic erosion'). Only fluff layer erosion (type Ia) occurred for juvenile bioturbators, except in the case of 1 experiment at the highest density (Fig. 4a). The fluff layer erosion (Ia) was characterized by a low sediment flux as shown by the slope of the curve during the first phases of the experiment. This type of erosion occurred also at low critical shear stress ( $\tau_{\text {crit-fluff }}$ ca 0.007 to $1.69 \mathrm{~Pa}$ ) and with low biomass of bioturbators. The bed erosion was not reached for most of the experiments with juveniles (with a lower biomass compared to adult cockles). The bed erosion (type $\mathrm{Ib}$ ) requires higher bed shear stress $\left(\tau_{\text {crit-bed }}\right.$ ca. 0.79 to $2.33 \mathrm{~Pa}$ ), and is accompanied by an important export of matter traduced by a more important slope of suspended matter (Fig. 4a). In intertidal ecosystem, such high hydrodynamic forces can be qualified of 'catastrophic erosion' since it can only be encountered during extreme phenomenon (in case of wind-induced stress).

The total resuspended chlorophyll $a$ (Fig. 4b) was estimated by artificially adding the quantity of chlorophyll $a$ filtrated by the cockle during the erosion experiment to the chlorophyll $a$ recorded by the probes (Fig. 4a). The maximum values of corrected suspended chlorophyll $a$ is 2 times greater than those recorded by the probe. However, on average, about $10 \%$ of suspended chlorophyll $a$ was filtrated by the cockle during the fluff layer erosion. In this work, the total amount of suspended chlorophyll $a\left(\mathrm{Chl} a_{\mathrm{tot}}\right)$ during the fluff layer erosion is used to perform the model parameterization of MPB resuspension under cockle bioturbation.

\subsection{Model calibration}

The bed shear stress measurements $\left(\tau_{\mathrm{f}}, \mathrm{Pa}\right)$ from each separate experiment were used as a forcing variable of the model (Fig.5c). The model was applied using the same bioturbator biomasses as the ones used during the laboratory experiments. Experimental results which consist of the total suspended chlorophyll $a$ kinetics $\left(\mathrm{Chl} a_{\mathrm{tot}}\right)$ is represented in the Fig. 5a. The corresponding simulations of suspended MPB in the water column ( $\mathrm{SChl} a$ ) is shown in 
the Fig. 5b. The sigmoidal pattern of resuspended chlorophyll $a$ is very well reproduced by the model (Fig. 5b). Moreover, the model realistically reproduces the lower scale of juvenile bioturbation impact on MPB erosion. The erosion of the biogenic matrix of sediment is indirectly represented by the evolution of the trace height over time in Fig. 6, with a maximum depth of eroded sediment of ca. $1 \mathrm{~mm}$. This figure represents the variation through time of the quantity of sediment and associated MPB from modeled sediment matrix under the bioturbation of cockle (represented by the depth of bioturbated matrix sediment uniformly distributed). A decrease of the modeled trace height over the incremental hydrodynamic forces was observed. At the end of the simulation, almost all the available MPB in the bioturbated matrix was resuspended in the water column as observed with the Fig. 6.

Modelling efficiency shows reasonable values on how the model reproduces the MPB bioresuspension (Tab. 3). Theil's inequality coefficient is also acceptable for the calibration step (Tab. 3). Moreover the test of equivalence rejected the null hypothesis of inequality with strict and relaxed tests (Tab. 4). The Q-Q plot (Fig. 5d) indicates some acceptable skewness and dispersion between observations and simulations.

\subsection{Biotic and abiotic characteristics of sampling sites}

The 3 sampled sites (A, B, and C) are different in terms of sediment properties, MPB biomasses and species assemblages. Analysis of macrofauna assemblage was conducted in the sampled sites. 10 major species were identified during the survey (Tab. 5). Analysis showed that the cockle dominates the assemblage in term of biomass in Baie des Veys about $98 \%$ all the time of the survey. The analysis also showed that about 3/4 of the macrofauna assemblage is constituted by species that actively rework sediment through movements (Tab. 5). Only two species are supposed to have a stabilizing effect on the sediment. Statistical analyses (Kruskal-Wallis) show significant differences in chlorophyll $a$ content between sites $(\mathrm{p}<0.01)$ and during the period of survey $(\mathrm{p}<0.05)$.

Site A is characterized by a sandy mud substrate. Average biomass of cockle ranges between 46 (in January 2013) to 403 (in April 2013) in gAFDW m ${ }^{-2}$ (Tab. 5). Deposit feeding annelid Scoloplos armiger is the second dominant species with a biomass ranging between 0.15 to $1.15 \mathrm{gAFDW} \mathrm{m}^{-2}$ followed by the Pygospio elegans, in which biomass varies from 0 to 0.03 gAFDW $\mathrm{m}^{-2}$. Statistical analysis shows a significant temporal variation of the chlorophyll $a$ content in the sediment in site A ( $\mathrm{p}<0.001)$. Analyses of the sediment chlorophyll $a$ content represented the lowest value $\left(1.50 \mu \mathrm{g} \mathrm{g}^{-1}\right)$ in April 2013 and a maximum value $\left(5.6 \mu \mathrm{g} \mathrm{g}^{-1}\right)$ in September 2012 (See Fig.7).

The sediment in site B was the muddiest of the three sites. The cockle always dominates the macrofauna, having a maximum biomass in January $2013\left(791 \mathrm{gAFDW} \mathrm{m}^{-2}\right.$ ) and a minimum biomass in April 2013 (110 gAFDW m ${ }^{-2}$ ). Macrofaunal assemblage analysis at this second site showed a complex composition compared to site A (Tab. 5). 3 among the 4 principal bioturbator species are clearly deposit-feeders, consuming MPB directly in the biofilm (Abra tenuis, Macoma balthica and Peringia ulvae). Analysis of chlorophyll $a$ included within the top centimeter of the sediment reveals the highest value among the sampling sites. The highest $\left(13.4 \mu \mathrm{g} \mathrm{g}^{-1}\right)$ and the lowest value $\left(4.88 \mu \mathrm{g} \mathrm{g}^{-1}\right)$ of chlorophyll $a$ in the sediment are observed respectively in January 2013 and in April 2013 in the site B. A significant temporal variation of the chlorophyll $a$ content in the sediment (Fig. 7) was observed in the second site $(\mathrm{p}<0.05)$. 
The last site (C) is the sandiest station located in the middle of the bay (closer to the river mouth) and where the highest biomass of cockles was recorded over the sampling period (Tab. 5). Cockle biomasses show a maximum value in January 2013 (2595 gAFDW $\mathrm{m}^{-2}$ ) and a minimum value in June 2012 (226 $\mathrm{gAFDW} \mathrm{m}^{-2}$ ). Several species constitute the macrofaunal assemblage but at a lower scale compared to the second site (lower biomasses). Presence of bioturbator (Scoloplos armiger) and MPB consumer and bioturbator such as Macoma balthica was also noticed in this site. No significant temporal variation of chlorophyll $a$ content in the sediment (Fig. 7) was highlighted by statistical analysis in the third site (p>0.05).

\subsection{Model validation}

Statistical analysis showed a significant spatial variability between the three sites. Thus, the validation of the model was performed site per site and with independent in situ data. The Fig. 8 represents the measurements of resuspended MPB at the three sites compared to the predicted resuspended MPB (Fig.8 A, B and C - Observations - Models). Time increases also suppose an increase in hydrodynamical forces over time (the real bed shear stress $\tau_{\mathrm{f}}$ measured during experiments).

Fig.8 shows that the model of suspended MPB displayed satisfying agreement with the dynamics of in situ bioresuspension in all seasons and in all locations. However, minor discrepancies are observed. The model slightly underestimates (Fig.8A - Q-Q plots) and overestimates (Fig.8 B and C - Q-Q plots) the bioresuspension. The modelling efficiency value shows a good agreement between observations and simulations as shown in the Tab. 3 for the 3 sites. Theil's inequality coefficient also show acceptable performance of the model. However, test of equivalence gives less favorable statement than the previous results and accepts the null hypothesis of inequality (Tab. 4) with both strict and relaxed tests for all sites. Contrary to calibration test of the model, the model using only cockle biomass to predict resuspension of microphytobenthos in the field. However, the lowest p-value was obtained in site B, which highlighted a moderate cockle biomass (Tab. 5). We explored some possibilities to improve the quality of adjustment during validation procedure, by analyzing the remained residuals between observed and predicted field data, especially in sites A and C, which showed the highest discrepancies between predicted and observed data.

All residuals of suspended chlorophyll $a$ were calculated and were confronted to sediment chlorophyll $a$ content and biomasses of macrofauna species to determine if the lack of fitting of the model could be explained by a specific stock of MPB in the sediment or specific macrofauna species. When plotted against chlorophyll $a$ content, residuals did not show any tendency (Figure not shown). Analysis with macrofauna did not show any tendency either, except for the species Pygospio elegans (Fig.9). At low biomass of this bioturbator, the residuals of resuspended chlorophyll $a$ were close to 0 . When the biomass increased (in the range of low values of Pygospio biomass $\sim 10^{2} \mathrm{mgAFDW} . \mathrm{m}^{-2}$ ), the residuals of suspended chlorophyll $a$ increased as a function of bioturbator density. After the critical value $\sim 10^{2}$ mgAFDW. $\mathrm{m}^{-2}$, the relationship shifted from a positive function to a negative one. At very high $P$. elegans biomass ( $>10^{3} \mathrm{mgAFDW} . \mathrm{m}^{-2}$ ), the residuals of suspended chlorophyll $a$ were negative.

5. Discussion

5.1 Effect of cockle on biological stabilization and destabilization of sediment 
Biological stabilization and destabilization figure among key processes that determine the extent of sediment erosion in estuaries. In most cases, biostabilization of the sediment has been attributed to MPB development. This is the case in the observations reported by Andersen et al. (2010), made during their erosion experiments. EPS (Extracellular Polymeric Substances) production takes place during motion of diatoms and has been stated to bond fine grains of sediment, thereby increasing the stability of the sediment (Tolhurst et al., 2006; Underwood and Paterson, 1993). Consequently, biostabilization of the sediment should lead to a difference between the outputs of the model and the in situ measurements of suspended chlorophyll $a$. When residuals of suspended chlorophyll $a$ were plotted against chlorophyll $a$ content of sediment, the later does not explain the observed discrepancy (slight overestimation of the model) between in situ data and simulations. Thus, biostabilization could be weakened by important faunal activity. Moreover, Orvain et al. (2007) did not observe either any stabilizing effect of MPB during their in situ analysis because the impact of macrofauna activity on sediment was significant.

In the case of cockles, opposite results have been observed about stabilizing (Andersen et al., 2010; Donadi et al., 2013a) and destabilizing effects (Ciutat et al., 2006, 2007; Neumeier et al., 2006) of this species on sediment. In our case, cockles enhance the erosion of sediment, allowing for the export of associated MPB. Cockles were fully buried within the sediment bed during erosion experiments, and surface irregularities were not provoked by the protruding shell but by the fluff layer formation of sediment surface. Change of roughness with cockle shells and sudden valve adduction during filtration, lead to more matter eroded to the water column. Our finding concurs with Neumeier et al. (2006), who report a way in which cockles create irregularities on sediment. Such irregularities constitute weak points where erosion starts.

Differences were observed in the effect of adult and juvenile cockles on the process of MPB resuspension (Fig. 4), which are due to the extent of bioturbation depending on the biomass. The higher the biomass, the higher the sediment reworked, and thus, the higher the resuspension of associated chlorophyll $a$. Sediment changes due to adult cockles are more important than with juvenile bioturbator. Bioturbation of adult cockles is also correlated to valve adduction during filtration at which time important erosion of sediment was noticed. Experimental results confirm that bioresuspension is greater with high biomass of bioturbator and is easily exported in the water column at low shear stress.

5.2 Model of MPB resuspension under cockle bioturbation

The model that we developed reproduces the resuspension of MPB associated with fluff layer erosion due to destabilization activity of the cockle. The model represents a simple monospecific bioturbator system. Biomass dependence of bioturbated matrix formation is well integrated in our model of fluff layer erosion and associated MPB (Eq. 11 and 12). The model uses a reduced number of parameters: the biomass specific bioturbation coefficient $A_{b t b}$ (Eq. 12) and the coefficient of erosion $\alpha$ (Eq. 10). Those parameters were estimated and provide satisfying calibration results (Fig. 5).

This study shows that, combined with bed shear stress $\left(\tau_{f}\right)$, the biomass of the main bioturbator can be the only factor involved in the bioresuspension of the MPB in sandy-mud ecosystems. The model apparently determines the resuspension process of MPB without recourse to a complex hydrodynamic model (e.g. Le Hir et al., 2000). Our study joins 
statement of Wood and Widdows (2002) that physical forces (tides) represents the driven factor of sediment erosion and biological component (macrofauna bioturbation) is able to drastically accentuate the process, especially in a highly changing system. The model simulates the erosion of the bioturbated surface of the sediment that contains important biomass of microalgae. This study points to the significant impact of the common cockle on the erosion of benthic diatoms in the water column which does not require high shear stress with (mean of $\tau_{\text {crit-fluff }}$ equals to $0.81+/-0.86 \mathrm{~Pa}$ ). Measurements conducted from 2009 and 2013 in the Baie des Veys (Lower Normandy, France) show that the cockle represents the major dominant species in terms of biomass (more than 98\%). The common cockle thus plays a decisive role on sediment erodibility in the bay scale. Analyses of model performance (Tab. 3) and tests of equivalence (Tab. 4) for the experimental data show that simulated resuspended MPB was reasonably similar to observed values both with strict and relaxed tests.

This study also reveals that the modified Partheniades formulation of Orvain et al. (2003), which describes the fluff layer erosion (Eq. 10), was applicable to a few bioturbator species with different behaviors (Peringia ulvae, Scrobicularia plana, Macoma balthica and Cerastoderma edule). The difference lays on the fluff layer creation, in other words to the species-specific bioturbation process. Orvain (2005) explains that the difference in bioturbation intensity is due to different mechanisms of bioturbation. The fluff layer formation was asymptotically related to bioturbator biomasses, for species like P. ulvae (Orvain et al., 2003) and M. balthica (van Prooijen et al., 2011; Willows et al., 1998), while it is linearly correlated to the density of $S$. plana (Orvain, 2005) and biomass of the cockle, $C$. edule in our case. Sediment reworking, burrowing activity and continuous valve adduction during filtration of cockle represent key processes on the resuspension of MPB in the water column. Change of roughness and turbulences caused by cockle in the surface when subjected to hydrodynamic forces were taken into account through the forcing variable of the model $\tau_{\mathrm{f}}$ represented. However, it is not within the scope of the mechanistic model that we developed. Consequently, the erosion fluxes are proportional to cockle biomasses when the cockle dominates the macrofaunal assemblages.

Then, the same parameters were used (without adjustment) to validate the model with independent in situ measurements (Fig. 8). The application in situ shows optimistic results as shown with the model performance indexes (Tab. 3). The general tendency of the suspended MPB kinetics is well reproduced by the model (Fig. 8 A-B-C) mainly for the site B where a high value of ME is observed. The results of equivalence tests should be taken with caution. Promising results is still observed with the site B with a low value of p-value despite the nonrejection of the inequality in all sites. It is important to notice that other macrofauna were present in the sediment which was not the case for the experimental design of calibration test. Several processes were not taken into account in our formulation such as bioturbation by other species (mainly in site B with diversified macrofauna composition), interaction between bioturbation effects and consumption by other species. The use of the model directly in situ and when cockle is not the main bioturbator is not recommended. The site with moderate biomass of cockles (site B) showed a better quality of adjustment during validation test.

\subsection{Integration of faunal community and food availability for upper consumers}


Our study reveals that the biomass of cockle is among the main factors that explain the MPB resuspension in the Baie des Veys. Fig. 6 highlights that the depth of sediment that is actually eroded because of cockle bioturbation can reach only 1 millimeter at most. We have put forth an analysis to determine the limits of the model by determining if the slight discrepancy of the model may be explained by specific macrofauna assemblage. Residual analysis on suspended chlorophyll $a$ showed that Pygospio elegans could explain the slight underestimation and overestimation of the model simulations compared to measurements (Fig. 9). On one hand, the deposit feeding behavior of this polychaete could induce MPB resuspension, at biomasses of about $10^{2} \mathrm{mg}$ AFDW $\mathrm{m}^{-2}$ in our case (Fig. 9). On the other hand, they become very efficient at actively capturing resuspended microalgae in a suspension-feeding activity and could stabilize sediment due to bioreef structure at biomasses $>10^{2} \mathrm{mg} \mathrm{AFDW} \mathrm{m}^{-2}$ in our case (Fig. 9). In their analyses, Orvain et al. (2007) have also found such contrasting effects with another species, the gastropod Peringia ulvae. Further studies need to be conducted to better evaluate the impact of $P$. elegans on sediment erodibility, cascade effects on MPB development, and availability for suspension-feeders after resuspension.

Improvements can thus be done with the model developed herein. A possible approach is to conduct analysis based on functional groups (Pearson, 2001) and to combine species with a similar bioturbation effect. For species with a similar impact as cockle, we can use the same set of equations, and biomass could be sufficient for the reproduction of MPB bioresuspension. Consequently, a species-specific model can be converted into a functional group model. Applied together, these 2 models could take into account a broad effect of community on sediment stability and consequently on MPB availability in estuarine ecosystem.

Ubertini (2012) observed evidence of enhancement of MPB development around the cockle burrow in absence of hydrodynamic forces especially for adult individuals. This process joins the facilitation of primary production by cockle noticed by Donadi et al. (2013b). This specific engineering mechanism by cockles could explain the discrepancies between studies on cockle bioturbation, since this species could simultaneously have 2 differing interactions: 1) a sediment-stabilizing effect of cockles promoted by the facilitation of MPB primary production, and 2) a chronic detachment of a part of the MPB standing stock by reworking effects of the sediment surface during feeding-related movements (the process modelled herein). In addition, cockles can have a third effect by modifying the bed roughness and increases the turbulent mixing in the benthic boundary layer. These changes also have a positive effect on the erosion flux by affecting the bed shear stress dynamics $\left(\tau_{\mathrm{f}}\right)$. Another possible improvement of the model is to integrate the facilitation of MPB development and primary production by cockle.

Analyzing MPB availability in estuarine system is crucial. Indeed, Lefebvre et al. (2009) noticed that macrofauna species switch their food source from phytoplankton to MPB differently. Moreover, Kang et al. (2006) demonstrated the importance of MPB during critical period and during phytoplankton shortfall. The contribution of MPB to suspension feeder diet was also highlighted over successive years (Grangeré et al., 2012).

\section{Conclusion}

This study has allowed us to characterize the cockle behavior and to model the capacity of this species in facilitating mud resuspension and associated MPB. We found that in a system 
where cockle dominates significantly the macrofaunal assemblage, biomass of cockle represents a relevant factor that determines the MPB resuspension. A model of MPB bioresuspension was calibrated with experimental data. The use of the model directly in situ is not recommended especially when cockle is not the main bioturbator and further improvement was discussed. The model represents a baseline in the simulation of benthic food availability for upper consumers as filter-feeders.

Acknowledgment:

This study was funded by the Regional council of Lower Normandy (Conseil Général de Basse Normandie) and the Water Agency Seine Normandy (Agence de l'Eau Seine Normandie). We would like to thank the "Reserve Naturelle Nationale du Domaine de Beauguillot". Thanks are expressed to Jean-François Elder, Franck Bruchon, Sebastien Lemaire, Christophe Roger, Romain Gosselin, and Laura Varin for their constructive help on this study. Many thanks to Samuele Tecchio and Andre Sesboüe for their valuable help. We also thank Catharine Mason for the correction of English. Finally, we would like to acknowledge the reviewer and the editor for the insightful comments that highly improve the quality of this work.

\section{LITERATURE CITED}

Amos, C.L., Daborn, G., Christian, H.., Atkinson, A., Robertson, A., 1992. In situ erosion measurements on fine-grained sediments from the Bay of Fundy. Mar. Geol. 108, 175196.

Andersen, T.J., Lanuru, M., van Bernem, C., Pejrup, M., Riethmueller, R., 2010. Erodibility of a mixed mudflat dominated by microphytobenthos and Cerastoderma edule, East Frisian Wadden Sea, Germany. Estuar. Coast. Shelf Sci. 87, 197-206.

Blanchard, G.F., Guarini, J.-M., Orvain, F., Sauriau, P.-G., 2001. Dynamic behaviour of benthic microalgal biomass in intertidal mudflats. J. Exp. Mar. Bio. Ecol. 264, 85-100.

Cancino, L., Neves, R., 1999. Hydrodynamic and sediment suspension modelling in estuarine systems: Part I: Description of the numerical models. J. Mar. Syst. 22, 105-116.

Chao, X., Jia, Y., Shields, F.D., Wang, S.S.Y., Cooper, C.M., 2008. Three-dimensional numerical modeling of cohesive sediment transport and wind wave impact in a shallow oxbow lake. Adv. Water Resour. 31, 1004-1014.

Ciutat, a, Widdows, J., Readman, J., 2006. Influence of cockle Cerastoderma edule bioturbation and tidal-current cycles on resuspension of sediment and polycyclic aromatic hydrocarbons. Mar. Ecol. Prog. Ser. 328, 51-64.

Ciutat, A., Widdows, J., Pope, N.D., 2007. Effect of Cerastoderma edule density on near-bed hydrodynamics and stability of cohesive muddy sediments. J. Exp. Mar. Bio. Ecol. 346, $114-126$.

Clarke, S., Elliott, A.J., 1998. Modelling Suspended Sediment Concentrations in the Firth of Forth. Estuar. Coast. Shelf Sci. 47, 235-250. 
Donadi, S., van der Heide, T., van der Zee, E.M., Eklöf, J.S., van de Koppel, J., Weerman, E.J., Piersma, T., Olff, H., Eriksson, B.K., 2013a. Cross-habitat interactions among bivalve species control community structure on intertidal flats. Ecology 94, 489-98.

Donadi, S., Weerman, E.J., Heide, T. Van Der, Zee, E.M. Van Der, Koppel, J. Van De, Olff, H., Veer, H.W. Van Der, Eriksson, B.K., 2013b. Non-trophic Interactions Control Benthic Producers on Intertidal Flats. Ecosystem.

Grangeré, K., Lefebvre, S., Blin, J.L., 2012. Spatial and temporal dynamics of biotic and abiotic features of temperate coastal ecosystems as revealed by a combination of ecological indicators. Estuar. Coast. Shelf Sci. 108, 109-118.

Guarini, J.-M., Sari, N., Moritz, C., 2008. Modelling the dynamics of the microalgal biomass in semi-enclosed shallow-water ecosystems. Ecol. Modell. 211, 267-278.

Guizien, K., Orvain, F., Duchêne, J.-C., Le Hir, P., 2012. Accounting for Rough Bed Friction Factors of Mud Beds as a Result of Biological Activity in Erosion Experiments. J. Hydraul. Eng. 138, 979-984.

Hedman, J.E., Gunnarsson, J.S., Samuelsson, G., Gilbert, F., 2011. Particle reworking and solute transport by the sediment-living polychaetes Marenzelleria neglecta and Hediste diversicolor. J. Exp. Mar. Bio. Ecol. 407, 294-301.

Jonsson, P., Petersen, J., Karlsson, Ö., Loo, L.-O., Nilsson, S., 2005. Particle depletion above experimental bivalve beds: In situ measurements and numerical modeling of bivalve filtration in the boundary layer. Limonology Oceanogr. 50, 1989-1998.

Kang, C., Lee, Y., Choy, E., Shin, J., Seo, I., Hong, J., 2006. Microphytobenthos seasonality determines growth and reproduction in intertidal bivalves. Mar. Ecol. Prog. Ser. 315, $113-127$.

Kristensen, E., Neto, J.M., Lundkvist, M., Frederiksen, L., Pardal, M.Â., Valdemarsen, T., Flindt, M.R., 2013. Influence of benthic macroinvertebrates on the erodability of estuarine cohesive sediments: Density- and biomass-specific responses. Estuar. Coast. Shelf Sci. 134, 80-87.

Kristensen, E., Penha-Lopes, G., Delefosse, M., Valdemarsen, T., Quintana, C., Banta, G., 2012. What is bioturbation? The need for a precise definition for fauna in aquatic sciences. Mar. Ecol. Prog. Ser. 446, 285-302.

Le Hir, P., Cann, P., Waeles, B., Jestin, H., Basoullet, P., 2008. Chapter 11 Erodibility of natural sediments: experiments on sand/mud mixtures from laboratory and field erosion tests. Proc. Mar. Sci. 9, 137-153.

Le Hir, P., Roberts, W., Cazaillet, O., Christie, M., Bassoulet, P., Bacher, C., 2000. Characterization of intertidal flat hydrodynamics. Cont. Shelf. 20, 1433-1459.

Lefebvre, S., Marín Leal, J.C., Dubois, S., Orvain, F., Blin, J.-L., Bataillée, M.-P., Ourry, A., Galois, R., 2009. Seasonal dynamics of trophic relationships among co-occurring 
suspension- feeders in two shellfish culture dominated ecosystems. Estuar. Coast. Shelf Sci. 82, 415-425.

Lo, Y.H., Blanco, J. a., Seely, B., Welham, C., (Hamish) Kimmins, J.P., 2011. Generating reliable meteorological data in mountainous areas with scarce presence of weather records: The performance of MTCLIM in interior British Columbia, Canada. Environ. Model. Softw. 26, 644-657.

Mariotti, G., Fagherazzi, S., 2012. Modeling the effect of tides and waves on benthic biofilms. J. Geophys. Res. 117.

Nelder, J. A. and Mead, R., 1965. A simplex method for function minimization. Comput. J. 7, $308-313$.

Neumeier, U., Lucas, C., Collins, M., 2006. Erodibility and erosion patterns of mudflat sediments investigated using an annular flume. Aquat. Ecol. 40, 543-554.

Orvain, F., 2005. A model of sediment transport under the influence of surface bioturbation: generalisation to the facultative suspension-feeder Scrobicularia plana. Mar. Ecol. Prog. Ser. 286, 43-56.

Orvain, F., Guizien, K., Lefebvre, S., Bréret, M., Dupuy, C., 2014. Relevance of macrozoobenthic grazers to understand the dynamic behaviour of sediment erodibility and microphytobenthos resuspension in sunny summer conditions. J. Sea Res.

Orvain, F., Hir, P., Sauriau, P., 2003. A model of fluff layer erosion and subsequent bed erosion in the presence of the bioturbator, Hydrobia ulvae. J. Mar. Res. 61, 823-851.

Orvain, F., Le Hir, P., Sauriau, P.-G., Lefebvre, S., 2012. Modelling the effects of macrofauna on sediment transport and bed elevation: Application over a cross-shore mudflat profile and model validation. Estuar. Coast. Shelf Sci. 108, 64-75.

Orvain, F., Sauriau, P., Hir, P. Le, Guillou, G., Cann, P., Paillard, M., 2007. Spatio-temporal variations in intertidal mudflat erodability: Marennes- Oléron Bay, western France. Cont. Shelf Res. 27, 1153-1173.

Orvain, F., Sauriau, P., Sygut, A., Joassard, L., Le Hir, P., 2004. Interacting effects of Hydrobia ulvae bioturbation and microphytobenthos on the erodibility of mudflat sediments. Mar. Ecol. Prog. Ser. 278, 205-223.

Partheniades, E., 1965. Erosion and deposition of cohesive soils. J. Hydr. Div. ASCE 91, 105.

Pearson, T.H., 2001. Functional group ecology in soft-sediment marine benthos: the role of bioturbation. Oceanogr. Mar. Biol. Annual Rev, 233 - 267.

Robinson, A.P., Duursma, R. a, Marshall, J.D., 2005. A regression-based equivalence test for model validation: shifting the burden of proof. Tree Physiol. 25, 903-913.

Robinson, A.P., Froese, R.E., 2004. Model validation using equivalence tests. Ecol. Modell. 176, 349-358. 
Rueda, J., Smaal, A., Scholten, H., 2005. A growth model of the cockle (Cerastoderma edule L.) tested in the Oosterschelde estuary (The Netherlands). J. Sea Res. 54, 276-298.

Shimeta, J., Amos, C.L., Beaulieu, S.E., Ashiru, O.M., 2002. Sequential resuspension of protists by accelerating tidal flow: Implications for community structure in the benthic boundary layer. Limnol. Oceanogr. 47, 1152-1164.

Sutherland, T.F., Grant, J., Amos, C.L., 1998. The effect of carbohydrate production by the diatom Nitzschia curvilineata on the erodibility of sediment. Limnol. Oceanogr. 43, 6572.

Tolhurst, T.J., Defew, E.C., De Brouwer, J.F.C., Wolfstein, K., Stal, L.J., Paterson, D.M., 2006. Small-scale temporal and spatial variability in the erosion threshold and properties of cohesive intertidal sediments. Cont. Shelf Res. 26, 351-362.

Toorman, E.A., 2002. Modelling of turbulent flow with suspended cohesive sediment. Fine Sediment Dyn. Mar. Environ. 155-169.

Ubertini, M., 2012. Déterminisme de la remise en suspension des diatomées benthiques au travers du couplage benthos-pelagos dans les écosystèmes côtiers bas-normands. University of Caen.

Ubertini, M., Lefebvre, S., Gangnery, A., Grangeré, K., Le Gendre, R., Orvain, F., 2012. Spatial variability of benthic-pelagic coupling in an estuary ecosystem: consequences for microphytobenthos resuspension phenomenon. PLoS One 7, e44155.

Underwood, G.J.C., Paterson, D.M., 1993. Seasonal changes in diatom biomass, sediment stability and biogenic stabilization in the Severn Estuary. J. Mar. Biol. Assoc. United Kingdom 73, 871-887.

Van Prooijen, B.C., Montserrat, F., Herman, P.M.J., 2011. A process-based model for erosion of Macoma balthica-affected mud beds. Cont. Shelf Res. 31, 527-538.

Vanclay, J.K., Skovsgaard, J.P., 1997. Evaluating forest growth models. Ecol. Modell. 98, 112.

Warner, J.C., Sherwood, C.R., Signell, R.P., Harris, C.K., Arango, H.G., 2008. Development of a three-dimensional, regional, coupled wave, current, and sediment-transport model. Comput. Geosci. 34, 1284-1306.

Welschmeyer A.N., 1994. Fluorometric analysis of chlorophyll a in the presence of chlorophyll b and pheopigments. Limnol. Oceanogr. 39, 1985-1992.

Widdows, J., Brinsley, M., 2002. Impact of biotic and abiotic processes on sediment dynamics and the consequences to the structure and functioning of the intertidal zone. J. Sea Res. 48, 143-156.

Willows, R., Widdows, J., Wood, R., 1998. Influence of an infaunal bivalve on the erosion of an intertidal cohesive sediment: a flume and modeling study. Limnol. Oceanogr. 43, 1332-1343. 
771 Wood, R., Widdows, J., 2002. A model of sediment transport over an intertidal transect, comparing the influences of biological and physical factors. Limnol. Oceanogr. 47, 848855.

774 
Fig.1 Sampling sites location (i). Quadruplicate samples of macrofauna and chlorophyll $a$ content of the sediment were conducted per station per site (ii grey circle). Triplicate samples of sediment cores were also conducted in three randomly chosen station per site (ii black circles).

Fig.2 Conceptualization of the model of MPB resuspension under cockle bioturbation. Simple arrow represents flux between the two compartments: the bioturbated layer $\left(\mathrm{Q}_{\mathrm{btb}}\right.$, gDWsediment $\mathrm{m}^{-2}$ ), the suspended matter (SPM, gDWsediment $\mathrm{m}^{-2}$ ). Sediment erosion is accompanied with MPB resuspension ( $\mathrm{SChl} a, \mu \mathrm{gChl} a \mathrm{~m}^{-2}$ ). The link between the two compartments is represented by the erosion flux $\left(\mathrm{E}_{\mathrm{btb}}\right.$, gDWsediment $\left.\mathrm{m}^{-2} \mathrm{~s}^{-1}\right)$. The filtration rate of cockle ( $\mathrm{Chl} a_{\mathrm{fil}}, \mu \mathrm{gChl} a \mathrm{~m}^{-2} \mathrm{~s}^{-1}$ ) was used to estimate the total amount of suspended MPB in the water column.

Fig. 3 Linear regression between cockle biomass and percentage of resuspended chlorophyll $a$ from the total microphytobenthic biomass in the sediment $\left(r^{2}=0.78\right)$.

Fig. 4 Chlorophyll $a$ concentration recorded in the Erodimeter (a) and cumulative chlorophyll $a$ concentration after filtration correction (b) as a function of time and depending on cockle biomass. Shear stress $\left(\tau_{\mathrm{f}}, \mathrm{Pa}\right)$ increases over time.

Fig. 5 Observed resuspended chlorophyll $a$ (a) and predicted eroded chlorophyll $a$ (b) as a function of time and depending on cockle biomass. Shear stress increases over time (c). Q-Q plot between observed and predicted suspended chlorophyll $a$ (d). The solid line represents $\mathrm{Y}=\mathrm{X}$ relationship. The kinetics of chlorophyll $a$ was restricted to the fluff layer erosion phase.

Fig. 6 Height $(\mathrm{m})$ of the bioturbated surface layer variation through time as a function of cockle biomass (gDWcockle $\mathrm{m}^{-2}$ )

Fig. 7 Chlorophyll $a$ content of the top centimeter of the sediment in three sites (A, B, and C) in June and September 2012 and January and April 2013.

Fig. 8 Observed suspended chlorophyll $a$ (Observations) and predicted suspended chlorophyll $a$ (Models) as a function of time and depending on the biomass of cockles in three location $(\mathrm{A}, \mathrm{B}, \mathrm{C})$ in the Baie des Veys-France. The solid line represents $\mathrm{Y}=\mathrm{X}$ relationship between observed and predicted suspended chlorophyll $a$ and Q-Q plots were built with averaged perstep data (during $5 \mathrm{~min}$ ) of observed and modeled erosion kinetics (Q-Q Plots).

Fig. 9 Residuals of suspended chlorophyll $a$ plotted against Pygospio elegans biomass (log transformed). The residuals represent the differences between the flume chlorophyll $a$ data and the simulated chlorophyll $a$. Each residual observation is obtained from the averaged residuals of resuspended chlorophyll $a$ of one experiment (at all time steps). 